\title{
Prevalence of the Rotator Cuff Tear Increases With Weakness in Hemiplegic Shoulder
}

\author{
Youbin Yi, $\mathrm{MD}^{1}$, Jae Seong Shim, $\mathrm{MD}^{1}$, Keewon Kim, $\mathrm{MD}^{1}$, So-Ra Baek, $\mathrm{MD}^{2}$, \\ Se Hee Jung, $\mathrm{MD}^{1}$, Won Kim, $\mathrm{MD}^{3}$, Tai Ryoon Han, $\mathrm{MD}^{1}$ \\ ${ }^{1}$ Department of Rehabilitation Medicine, Seoul National University College of Medicine, Seoul; \\ ${ }^{2}$ Department of Rehabilitation Medicine, Kangwon National University School of Medicine, Chuncheon; \\ ${ }^{3}$ Department of Rehabilitation Medicine, Asan Medical Center, University of Ulsan College of Medicine, Seoul, Korea
}

Objective To investigate the relationship between the rotator cuff tear (RCT) and the muscle strength in hemiplegic side, and the effects of paralysis on the affected shoulders in hemiplegic patients.

Methods A cross-sectional observational study performed in a university hospital was presented. The study enrolled 55 participants with hemiplegia of diverse degree of motor paresis, excluding those with bilateral lesions, history of major trauma or other co-existing musculoskeletal disorders of the shoulder. The main outcome measurements were muscle strength of the affected upper extremity (based on Medical Research Council scale), RCTs of the bilateral shoulders (by ultrasonography), and presence of shoulder pain, subluxation of the glenohumeral joint, passive range of motions, and subacromial spurs.

Results Comparing each side of the shoulders, the prevalence of shoulder pain and supraspinatus muscle tear was higher $(\mathrm{p}<0.0001, \mathrm{p}=0.007)$, and the range of motion was restricted $(\mathrm{p}<0.0001, \mathrm{p}<0.0001, \mathrm{p}<0.0001, \mathrm{p}<0.0001)$ in the affected side. There was a significant trend toward higher prevalence of RCT and shoulder subluxation in the weaker shoulder $(\mathrm{p}=0.019, \mathrm{p}<0.0001)$. In a multivariate analysis, Manual Muscle Test grade of less than three was an independent risk factor for RCT ( $\mathrm{p}=0.025)$.

Conclusion RCT in hemiplegia had a linear trend with muscle weakness in the affected side and the degree of weakness was an independent risk factor for the occurrence of RCT. In addition, shoulder pain, limitation of range of motions, and RCT were more frequent on the hemiplegic side of the shoulders. It is the first study to reveal a linear trend between RCT and upper extremity weakness and will provide physicians an insight to the management of RCTs in hemiplegic patients.

Keywords Hemiplegia, Shoulder, Rotator cuff, Tendon injuries

Received February 1, 2013; Accepted April 29, 2013

Corresponding author: Tai Ryoon Han

Department of Rehabilitation Medicine, Seoul National University

Hospital, 101 Daehak-ro, Jongno-gu, Seoul 110-744, Korea

Tel: +82-2-2072-3218, Fax: +82-2-743-7473, E-mail: tairyoon@snu.ac.kr

(c) This is an open-access article distributed under the terms of the Creative Commons Attribution Non-Commercial License (http://creativecommons. org/licenses/by-nc/3.0) which permits unrestricted noncommercial use, distribution, and reproduction in any medium, provided the original work is properly cited.

Copyright $\odot 2013$ by Korean Academy of Rehabilitation Medicine

\section{INTRODUCTION}

Hemiplegic shoulder pain (HSP) is one of the most common problems after stroke [1-3]. HSP impedes rehabilitation and adversely affects the functional gain [47]. Despite the high prevalence and clinical importance, literatures regarding HSP reported conflicting findings regarding the incidence, risk factors, etiology, and treat- 
ments. Such discordance partly stems from the differences in the definition of HSP, population characteristics, or the timing of examination among the studies. Thus far, several factors have been proposed as causes of HSP: adhesive capsulitis, complex regional pain syndrome, rotator cuff tear (RCT), joint subluxation, spasticity, and others [7-11].

Among them, RCTs have claimed attention as a considerable portion of the cause of HSP $[8,12]$. However, there is a controversy over their causal relationship between RCT and hemiplegia. Some studies observed an increased prevalence of RCTs in hemiplegic shoulders compared to the contralateral one or normal control $[12,13]$, and indicated that HSP from RCTs could be markedly reduced by injecting local anesthetics injection into the subacromial space based on the postulate in which the cuff tendons being impinged against the acromion in hemiplegic shoulders [8]. In contrast, other studies found no difference in the incidence of RCT between the affected and unaffected sides, or between hemiplegic and control groups $[7,9,10]$. Hakuno et al. [9] reported that RCT in hemiplegia were associated with premorbid shoulder pain, not with HSP. The disagreement among studies confuses physicians with the clinical significance of RCT in hemiplegia and treatment of HSP.

Various factors are attributed to the pathogenesis of RCTs, in the general condition. The causative factors of RCT can be divided into the extrinsic and intrinsic ones [14]. Extrinsic factors include anatomical variances, such as the shape of the acromion [15-17], intense mechanical activities or traumatic injuries [18-20]. Intrinsic factors primarily refer to degeneration from aging or repetitive microtrauma [21,22], histologic properties, such as hypovascularity [23-25], biochemical or biomechanical milieu [26] or oxidative stresses [27-29]. If RCTs do develop in hemiplegic shoulders, either intrinsic or extrinsic factors can be suspected to elicit RCTs. For instance, hemiplegic patients may experience alteration of biomechanical or biochemical properties of the rotator cuffs, or they may also be vulnerable to external trauma without appropriate protection by active movement. At any case, motor weakness in hemiplegia can be presumed, with logical plausibility, to be in relation to RCTs.

Therefore, the present study was conducted to investigate the relationship between the RCT and the motor weakness of hemiplegia, and other effects of the paralysis on the affected shoulders in hemiplegic patients.

\section{MATERIALS AND METHODS}

\section{Participants}

We recruited study participants from the tertiary referral, university hospital in a metropolitan between April 2007 and March 2009. Eligible participants were patients with HSP secondary to strokes or other brain lesions. Hemiplegia was diagnosed when they developed unilateral weakness of sudden onset, which was compatible with brain lesions confirmed by imaging studies, such as magnetic resonance image or computed tomography of the brain. Patients were excluded if 1) weakness was bilateral, 2) any history of intensive trauma of the shoulder was reported, or 3) known musculoskeletal problems of the shoulder preexisted.

The study protocol was approved by the Institutional Review Board of the hospital and all participants gave informed consent.

\section{Outcome measurement}

The patients' demographic data, regarding sex, age, height, weight, duration of hemiplegia, presence of diabetes, hemiplegic side, and profiles of the brain lesion were collected. All the participants were asked whether they have pain on either side of their shoulder.

\section{Muscle strength}

Physicians evaluated muscle strength of the upper extremity by Manual Muscle Test (MMT), following the Medical Research Council scale. The strength of elbow flexion, with the forearm in supination, represented the upper extremity strength in this study; although shoulder abduction might be more appropriate to indicate proximal strength of the upper extremity, it was not adopted with the concern of the influence by rotator cuff disorders.

\section{Range of motions}

Passive range of motions (ROMs) was measured with goniometer, while the patient sitting on a stool. Abduction, forward flexion and external rotation were measured, with the subject asked to relax as much as possible, and the examiner pressing down on the clavicle and scapula with one hand. 


\section{Subluxation on physical examination}

The subluxation of the glenohumeral joint was examined by palpating the subacromial regions of the both sides and compared the affected side with the unaffected side, while patients were seated and relaxed. When palpated space between the acromion and the humeral head was wider than the unaffected side by one half finger breadth or more, it was judged to be the subluxation.

\section{Radiologic findings}

For subjects who had a shoulder X-rays on the day of the examination, the official records of the X-rays were reviewed for checking the presence of subluxations or subacromial spurs on the affected shoulders.

\section{Sonographic findings}

All participants received sonographic evaluations of the both, affected and unaffected, shoulders (Accuvix
V20; Medison, Seoul, Korea). Ultrasonography routinely checked whether the shoulder contains long biceps tendon sheath swelling, rotator cuff tear, or acromioclavicular joint degeneration.

\section{Statistical analysis}

The demographic variables (sex, age, height, weight, duration of hemiplegia, diabetes, and profiles of the brain lesions) and clinical parameters (shoulder subluxation, subacromial spur, and shoulder pain) were compared among the five groups divided by the upper extremity motor power. Since the sample size was not large enough to guarantee normal distribution, Pearson $\chi^{2}$ or Fisher exact tests and Kruskal-Wallis tests were used. The information about the shoulder on the affected and unaffected side was compared between them, using McNemar and Wilcoxon signed-rank tests. A linear-bylinear association was used to compare the ordinal vari-

Table 1. Demographic and clinical variables of the participants

\begin{tabular}{|c|c|c|c|c|c|c|}
\hline \multirow[b]{2}{*}{ Variable } & \multicolumn{5}{|c|}{ Manual Muscle Test } & \multirow[b]{2}{*}{ p-value } \\
\hline & $\begin{array}{c}\text { Grade } 0 \\
(\mathrm{n}=11)\end{array}$ & $\begin{array}{c}\text { Grade } 1 \\
(n=14)\end{array}$ & $\begin{array}{c}\text { Grade } 2 \\
(n=9)\end{array}$ & $\begin{array}{c}\text { Grade } 3 \\
(\mathrm{n}=11)\end{array}$ & $\begin{array}{c}\text { Grade } 4 \\
(n=10)\end{array}$ & \\
\hline \multicolumn{7}{|l|}{ Demographic } \\
\hline Sex, male & $4(36)$ & $8(57)$ & $5(56)$ & $5(45)$ & $6(60)$ & 0.828 \\
\hline Age (yr) & $64.7 \pm 10.2$ & $59.9 \pm 14.3$ & $61.7 \pm 9.2$ & $67.4 \pm 12.5$ & $64.6 \pm 13.8$ & 0.393 \\
\hline Height $(\mathrm{cm})$ & $158.2 \pm 10.0$ & $163.5 \pm 9.1$ & $159.1 \pm 6.0$ & $165.8 \pm 10.7$ & $163.1 \pm 10.0$ & 0.363 \\
\hline Weight (kg) & $57.4 \pm 6.1$ & $58.9 \pm 9.5$ & $56.0 \pm 9.3$ & $60.3 \pm 10.8$ & $58.3 \pm 7.3$ & 0.963 \\
\hline $\begin{array}{l}\text { Duration of hemiplegia (day), } \\
\text { median (range) }\end{array}$ & $41(17-197)$ & $28(6-163)$ & $57(25-120)$ & $33(22-166)$ & $26(15-97)$ & 0.100 \\
\hline Diabetes & $5(45)$ & $4(29)$ & $4(44)$ & $3(27)$ & $4(40)$ & 0.844 \\
\hline Hemiplegic side, right & $3(27)$ & $6(43)$ & $2(22)$ & $2(18)$ & $3(30)$ & 0.767 \\
\hline \multicolumn{7}{|l|}{ Profiles of the brain lesions } \\
\hline Infarction & $7(64)$ & $9(64)$ & $6(67)$ & $9(82)$ & $7(70)$ & 0.900 \\
\hline Hemorrhage & $4(36)$ & $5(36)$ & $2(22)$ & $2(18)$ & $2(20)$ & 0.819 \\
\hline Tumor & $0(0)$ & $0(0)$ & $1(11)$ & $0(0)$ & $1(10)$ & 0.189 \\
\hline \multicolumn{7}{|l|}{ Clinical } \\
\hline \multicolumn{7}{|l|}{ Subluxation } \\
\hline On physical exam & $9(82)$ & $13(93)$ & $7(78)$ & $5(45)$ & $1(10)$ & $<0.001^{\mathrm{a})}$ \\
\hline On X-rays & $6 / 10(60)$ & $9 / 11(82)$ & $1 / 5(20)$ & $2 / 8(25)$ & $0 / 7(0)$ & $0.003^{a)}$ \\
\hline Subacromial spur & $5 / 10(50)$ & $1 / 13(8)$ & $2 / 5(40)$ & $2 / 8(25)$ & $3 / 7(43)$ & 0.172 \\
\hline \multicolumn{7}{|l|}{ Shoulder pain } \\
\hline Affected side & $6(55)$ & $10(71)$ & $5(56)$ & $9(82)$ & $2(20)$ & 0.050 \\
\hline Unaffected side & $1(9)$ & $0(0)$ & $0(0)$ & $1(9)$ & $0(0)$ & 0.613 \\
\hline
\end{tabular}

Values are presented as number (\%) or mean \pm standard deviation. ${ }^{\text {a) }} \mathrm{p}<0.01$. 
ables, as needed. To determine the independent risk factors for RCT, a multiple regression analysis with logistic model was used to control for the effects of confounding variables. The significance level was determined at $5 \%$, and all statistical analyses were performed using SPSS software (SPSS Inc., Chicago, IL, USA).

\section{RESULTS}

\section{Demographic and clinical parameters}

Among the included 55 patients, twenty-eight patients (51\%) were male sex, and the mean age was 63.5 years old. Thirty-eight patients (69\%) had infarction, fifteen (27\%) had hemorrhage, and two (4\%) had tumor for the etiology of the hemiplegia. The duration from the hemiplegia onset to the examination was 54.0 days (range, 6-197 days). Sixteen patients (29\%) had hemiplegia on the right side and twenty patients (36\%) had diabetes.

Eleven, 14, 9, 11, and 10 patients presented upper extremity muscle power of MMT grade $0,1,2,3$, and 4 (Table 1). All the demographic variables were comparable among the five groups. The prevalence of subacromial spur and shoulder pain on each side showed no statistical differences as well. However, shoulder subluxation was statistically different among those groups $(\mathrm{p}<0.001$

Table 2. Effect of hemiplegia on the shoulder

\begin{tabular}{|c|c|c|c|}
\hline & $\begin{array}{l}\text { Affected } \\
\text { side } \\
(n=55)\end{array}$ & $\begin{array}{c}\text { Unaffected } \\
\text { side } \\
(n=55)\end{array}$ & $\begin{array}{c}\text { p- } \\
\text { value }\end{array}$ \\
\hline Shoulder pain & $32(58)$ & $2(4)$ & $<0.001^{\text {a) }}$ \\
\hline \multicolumn{4}{|l|}{ Sonographic findings } \\
\hline LBT sheath swelling & $18(33)$ & $10(18)$ & 0.057 \\
\hline Subscapularis tear & $2(4)$ & $4(7)$ & 0.687 \\
\hline Degenerative AC joint & $6(11)$ & $4(7)$ & 0.687 \\
\hline Supraspinatus tear & $30(55)$ & $16(29)$ & $0.007^{\mathrm{a})}$ \\
\hline Infraspinatus tear & $1(2)$ & $0(0)$ & 1.000 \\
\hline \multicolumn{4}{|l|}{ Range of motions $\left({ }^{\circ}\right)$} \\
\hline Abduction & $103.7 \pm 17.5$ & $117.3 \pm 9.1$ & $<0.001^{\text {a) }}$ \\
\hline Forward flexion & $131.8 \pm 25.6$ & $145.0 \pm 17.0$ & $<0.001^{\text {a) }}$ \\
\hline External rotation & $71.5 \pm 22.4$ & $84.1 \pm 11.7$ & $<0.001^{\text {a) }}$ \\
\hline Internal rotation & $73.4 \pm 21.2$ & $83.8 \pm 14.3$ & $<0.001^{\text {a) }}$ \\
\hline
\end{tabular}

Values are presented as number (\%) or mean \pm standard deviation.

LBT, long biceps tendon; AC, acromioclavicular.

${ }^{\text {a) }} \mathrm{p}<0.01$. for subluxations on physical exams, $\mathrm{p}=0.003$ for those on the X-rays).

\section{Effect of hemiplegia on the shoulder}

The affected and unaffected shoulders of 55 hemiplegia patients were compared between them (Table 2). The prevalence of shoulder pain and supraspinatus muscle tear were significantly different between the two groups ( $\mathrm{p}<0.001$ and $\mathrm{p}=0.007$, respectively). ROMs to all directions-abduction, forward flexion, external rotation, and internal rotation-also presented statistical differences between the two groups $(\mathrm{p}<0.001, \mathrm{p}<0.001, \mathrm{p}<0.001$, $\mathrm{p}<0.001$, respectively).

\section{Muscle strength and rotator cuff tear}

RCTs and shoulder subluxations according to the upper extremity muscle strength were shown (Fig. 1). A significant trend toward higher prevalence of RCT and shoulder subluxation in weaker motor power was demonstrated using a linear-by-linear association $(\mathrm{p}=0.019$ and $\mathrm{p}<0.001$, respectively).

A multivariate analysis with logistic regression model for RCTs adjusting sex, age, duration of hemiplegia, hemiplegic side, diabetes, and motor function of the upper extremity-MMT grade weaker than three-was also demonstrated (Table 3). Upper extremity muscle strength weaker than grade three was identified as an independent risk factor for $\mathrm{RCT}(\mathrm{p}=0.025$, odds ratio $=4.23)$.

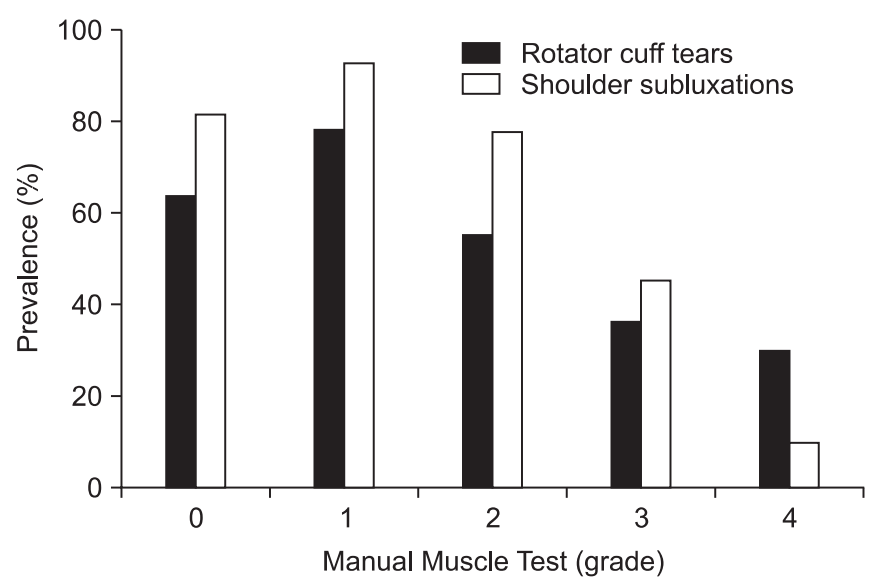

Fig. 1. Rotator cuff tears and shoulder subluxations according to the motor function. A trend toward higher prevalence of rotator cuff tear and shoulder subluxation in weaker upper extremities was demonstrated $(\mathrm{p}=0.019$ and $p<0.001$, respectively; using linear-by-linear association). 
Table 3. Multivariate analysis with logistic regression model for rotator cuff tears

\begin{tabular}{lll}
\hline & p-value & \multicolumn{1}{c}{ OR (95\% CI) } \\
\hline Sex, female & 0.595 & $1.59(0.46-5.51)$ \\
Age & 0.451 & $1.03(0.97-1.09)$ \\
Duration of hemiplegia & 0.208 & $1.01(0.99-1.02)$ \\
Hemiplegic side & 0.347 & $1.93(0.49-7.63)$ \\
Diabetes & 0.733 & $1.26(0.34-4.69)$ \\
Motor function (MMT Gr $<3)$ & $0.025^{\mathrm{a}}$ & $4.23(1.19-14.97)$ \\
\hline
\end{tabular}

OR, odds ratio; CI, confidence interval; MMT Gr, Manual Muscle Test grade.

${ }^{a)} \mathrm{p}<0.05$.

\section{DISCUSSION}

The purpose of this study was to investigate the relationship between the RCT and muscle strength in the hemiplegic side, and the effects of the paralysis on the affected shoulders in hemiplegic patients. It was demonstrated that hemiplegic shoulder have higher prevalence of shoulder pain, supraspinatus tear, and limited ROMs. A significant trend toward higher prevalence of RCT and shoulder subluxation in weaker upper extremity motor power was observed, and the muscle strength was identified as an independent predisposing factor for the RCT.

The results of the current study correspond with the previous studies that demonstrated increased prevalence of the RCT in hemiplegia $[8,12,13]$, but disagree with other reports that suggested no association between them $[7,9,10]$. However, our results may explain the existing disagreement among the previous studies. The observation that the occurrence of RCT in hemiplegia was dependent on the severity of motor weakness suggests that the association of RCT with hemiplegia can be altered, according to the distribution of motor paresis within the study populations. That is, studies that recruited patients of milder paresis would document equivocal association between RCT and hemiplegia $[7,11]$, while studies with participants of more severe paresis would reveal a significant association between them $[9,13]$.

Our results suggest several explanations on how RCT can develop in hemiplegic shoulders. First, increased tension on the rotator cuff tendon might induce its biomechanical failure. According to the experiments about mechanical properties of the glenohumeral joint, the supraspinatus tendon was reported as the strongest static stabilizer against inferior translation of the humerus [30,31]. However, in the circumstances where the dynamic stabilizers, such as deltoid and other shoulder girdle muscles, fail to sustain the downward force of the gravity, just as in hemiplegia, the supraspinatus tendon is inevitably exposed to the increased tensile load [30,32]. The weaker the muscle strength, the more tension is imposed on the supraspinatus tendon. Although the tendon would maintain its integrity within the tolerable range of stress-strain relationship, a prolonged tensile overload may cause mechanical fatigue, loss of elasticity and eventually the tear of the tendon. That scheme is substantiated by the observation that most RCTs of the hemiplegic shoulder involved the articular side of the supraspinatus; 28 tears out of 33 were on the articular side and 30 tears were in the supraspinatus tendon. It is worth to note that the articular side of the tendon can endure less tension and less deformation than the bursal side [26]. Second, paretic shoulder girdle muscles may predispose rotator cuff tendons to repetitive trauma. Altered kinetics of the shoulder in hemiplegia might provoke impingement at the subacromial space $[33,34]$ or there may be iatrogenic soft tissue injuries caused by passive mobilization of the shoulder during a routine physiotherapy for rehabilitation $[35,36]$. In such cases, the absence of protective, coordinated movement by active contraction would probably aggravate the rotator cuff tendinopathy.

In this study, shoulder subluxation also had a trend according to the muscle strength on the hemiplegic side. It was significantly different among the five groups divided by motor power as well. There is a possibility that the presence of shoulder subluxation in weaker upper extremity strength might predispose or precipitate RCTs. On the contrary, another possibility that apparent RCTs in weaker shoulder might entail the subluxation is also present. These possibilities cannot be differentiated in this study. However, it can hardly be contradicted that the weakness is a preceding condition for the subluxation, and thus, the current study was focused on the occurrence of RCT in relation to the severity of paresis.

Meanwhile, not only supraspinatus tear, but also shoulder pain and limitation of ROM were more common in the affected side. However, there was no trend between the motor power of affected shoulder and shoulder pain or limitation of ROMs. Other previous studies did not 
reveal a definite relationship of RCT to HSP [9,37], either, suggesting that RCT may not be the main pathology of HSP. In addition, most degenerative RCTs were known to be asymptomatic [1] in the aged population; the RCT in hemiplegic shoulder might be pathophysiologically analogous to asymptomatic degenerative RCTs. Therefore, the results of higher prevalence of pain and limitation of ROM in the affected shoulder might be coincidental findings, which may be present in the hemiplegic shoulders.

This is the first study that demonstrated a difference of the prevalence of RCT among the different upper extremity muscle strength groups. The results presented a strong trend toward higher prevalence of RCT in weaker upper extremities, and pointed out that the motor function of the affected side may be the independent predisposing factor for the RCTs.

On the other hand, the prevalence of RCT in this study was up to $55 \%$ and was much higher than the previous cadaveric study result of $30 \%$ [1]. However, the current study included patients with HSP, in contrast to the cadaveric study, which recruited both symptomatic and asymptomatic subjects. Further, the observed prevalence was similar with the previously reported prevalence of RCT in HSP, 50\% [11] and 40\% [38].

There are a few limitations to be considered in our study. Most of all, since the subject collection was not randomized, the study population may not represent crude hemiplegic patients. Second, the study was designed as a cross-sectional study. Thus, the association between weakness and RCTs cannot necessarily indicate their causal relationship. Third, the sample size was not large enough to evaluate the associations of various clinical parameters with RCT or HSP. The sample size was calculated to test the association between hemiplegia and RCT, and the correlation of RCT with muscle weakness; other hypotheses were not included in the design of the study. Lastly, we measured elbow flexion to evaluate the upper extremity motor power to prevent shoulder pain from interfering with shoulder motor power measurement. However shoulder abductor or flexor power would have a more close relationship with the mechanism of RCTs. Further study with larger sample size and longitudinal follow-up may confirm the causality between the hemiplegia and RCT or evaluate other possible relationship among the other factors.

In conclusion, RCT in hemiplegia had a linear trend with muscle weakness in the affected side and the weakness might be the independent risk factor for the occurrence of RCT. In addition, shoulder pain, limitation of ROMs, and RCT were more frequent on the hemiplegic of shoulders. It is the first study to reveal a linear trend between RCT and weakness of the hemiplegia, and will provide physicians an insight to the management of RCTs in hemiplegic patients. Further research with longitudinal follow-up may provide more information regarding the mechanism of RCT.

\section{CONFLICT OF INTEREST}

No potential conflict of interest relevant to this article was reported.

\section{REFERENCES}

1. Reilly P, Macleod I, Macfarlane R, Windley J, Emery RJ. Dead men and radiologists don't lie: a review of cadaveric and radiological studies of rotator cuff tear prevalence. Ann R Coll Surg Engl 2006;88:116-21.

2. Sano H, Ishii H, Trudel G, Uhthoff HK. Histologic evidence of degeneration at the insertion of 3 rotator cuff tendons: a comparative study with human cadaveric shoulders. J Shoulder Elbow Surg 1999;8:574-9.

3. Lindgren I, Jonsson AC, Norrving B, Lindgren A. Shoulder pain after stroke: a prospective populationbased study. Stroke 2007;38:343-8.

4. Yu D. Shoulder pain in hemiplegia. Phys Med Rehabil Clin N Am 2004;15:vi-vii, 683-97.

5. Bender L, McKenna K. Hemiplegic shoulder pain: defining the problem and its management. Disabil Rehabil 2001;23:698-705.

6. Gilmore PE, Spaulding SJ, Vandervoort AA. Hemiplegic shoulder pain: implications for occupational therapy treatment. Can J Occup Ther 2004;71:36-46.

7. Van Ouwenaller C, Laplace PM, Chantraine A. Painful shoulder in hemiplegia. Arch Phys Med Rehabil 1986;67:23-6.

8. Joynt RL. The source of shoulder pain in hemiplegia. Arch Phys Med Rehabil 1992;73:409-13.

9. Hakuno A, Sashika H, Ohkawa T, Itoh R. Arthrographic findings in hemiplegic shoulders. Arch Phys Med Rehabil 1984;65:706-11.

10. Rizk TE, Christopher RP, Pinals RS, Salazar JE, Higgins 
C. Arthrographic studies in painful hemiplegic shoulders. Arch Phys Med Rehabil 1984;65:254-6.

11. Lo SF, Chen SY, Lin HC, Jim YF, Meng NH, Kao MJ. Arthrographic and clinical findings in patients with hemiplegic shoulder pain. Arch Phys Med Rehabil 2003;84:1786-91.

12. Najenson T, Yacubovich E, Pikielni SS. Rotator cuff injury in shoulder joints of hemiplegic patients. Scand J Rehabil Med 1971;3:131-7.

13. Nepomuceno CS, Miller JM 3rd. Shoulder arthrography in hemiplegic patients. Arch Phys Med Rehabil 1974;55:49-51.

14. Wolff AB, Sethi P, Sutton KM, Covey AS, Magit DP, Medvecky M. Partial-thickness rotator cuff tears. J Am Acad Orthop Surg 2006;14:715-25.

15. Neer CS 2nd. Anterior acromioplasty for the chronic impingement syndrome in the shoulder. 1972. J Bone Joint Surg Am 2005;87:1399.

16. MacGillivray JD, Fealy S, Potter HG, O'Brien SJ. Multiplanar analysis of acromion morphology. Am J Sports Med 1998;26:836-40.

17. Wang JC, Horner G, Brown ED, Shapiro MS. The relationship between acromial morphology and conservative treatment of patients with impingement syndrome. Orthopedics 2000;23:557-9.

18. Yamaguchi K, Ditsios K, Middleton WD, Hildebolt CF, Galatz LM, Teefey SA. The demographic and morphological features of rotator cuff disease: a comparison of asymptomatic and symptomatic shoulders. J Bone Joint Surg Am 2006;88:1699-704.

19. Jobe CM. Superior glenoid impingement. Orthop Clin North Am 1997;28:137-43.

20. Blevins FT. Rotator cuff pathology in athletes. Sports Med 1997;24:205-20.

21. Soslowsky LJ, Thomopoulos S, Tun S, Flanagan CL, Keefer CC, Mastaw J, et al. Neer Award 1999. Overuse activity injures the supraspinatus tendon in an animal model: a histologic and biomechanical study. J Shoulder Elbow Surg 2000;9:79-84.

22. Perry SM, McIlhenny SE, Hoffman MC, Soslowsky LJ. Inflammatory and angiogenic mRNA levels are altered in a supraspinatus tendon overuse animal model. J Shoulder Elbow Surg 2005;14(1 Suppl S):79S-83S.

23. Lohr JF, Uhthoff HK. The microvascular pattern of the supraspinatus tendon. Clin Orthop Relat Res 1990;(254):35-8.
24. Rothman RH, Parke WW. The vascular anatomy of the rotator cuff. Clin Orthop Relat Res 1965;41:176-86.

25. Rathbun JB, Macnab I. The microvascular pattern of the rotator cuff. J Bone Joint Surg Br 1970;52:540-53.

26. Nakajima T, Rokuuma N, Hamada K, Tomatsu T, Fukuda $\mathrm{H}$. Histologic and biomechanical characteristics of the supraspinatus tendon: reference to rotator cuff tearing. J Shoulder Elbow Surg 1994;3:79-87.

27. Yuan J, Murrell GA, Wei AQ, Wang MX. Apoptosis in rotator cuff tendonopathy. J Orthop Res 2002;20:13729.

28. Yuan J, Murrell GA, Trickett A, Wang MX. Involvement of cytochrome c release and caspase- 3 activation in the oxidative stress-induced apoptosis in human tendon fibroblasts. Biochim Biophys Acta 2003;1641:3541.

29. Yuan J, Murrell GA, Trickett A, Landtmeters M, Knoops B, Wang MX. Overexpression of antioxidant enzyme peroxiredoxin 5 protects human tendon cells against apoptosis and loss of cellular function during oxidative stress. Biochim Biophys Acta 2004;1693:3745.

30. Soslowsky LJ, Malicky DM, Blasier RB. Active and passive factors in inferior glenohumeral stabilization: a biomechanical model. J Shoulder Elbow Surg 1997;6:371-9.

31. Ovesen J, Nielsen S. Experimental distal subluxation in the glenohumeral joint. Arch Orthop Trauma Surg 1985;104:78-81.

32. Halder AM, Halder CG, Zhao KD, O'Driscoll SW, Morrey BF, An KN. Dynamic inferior stabilizers of the shoulder joint. Clin Biomech (Bristol, Avon) 2001;16: 138-43.

33. Niessen M, Janssen T, Meskers C, Koppe P, Konijnenbelt M, Veeger D. Kinematics of the contralateral and ipsilateral shoulder: a possible relationship with poststroke shoulder pain. J Rehabil Med 2008;40:482-6.

34. Diederichsen LP, Norregaard J, Dyhre-Poulsen P, Winther A, Tufekovic G, Bandholm T, et al. The activity pattern of shoulder muscles in subjects with and without subacromial impingement. J Electromyogr Kinesiol 2009;19:789-99.

35. Gold GE, Pappas GP, Blemker SS, Whalen ST, Campbell G, McAdams TA, et al. Abduction and external rotation in shoulder impingement: an open MR study on healthy volunteers initial experience. Radiology 
2007;244:815-22.

36. Pong YP, Wang LY, Wang L, Leong CP, Huang YC, Chen YK. Sonography of the shoulder in hemiplegic patients undergoing rehabilitation after a recent stroke. J Clin Ultrasound 2009;37:199-205.

37. Kim HA, Kim SH, Seo YI. Ultrasonographic findings of painful shoulders and correlation between physical examination and ultrasonographic rotator cuff tear. Mod Rheumatol 2007;17:213-9.

38. Yoon TS, Kim DH, Park JW, Kwon BS, Ryu KH, Lee HJ, et al. Causes of the hemiplegic shoulder pain. J Korean Acad Rehabil Med 2010;34:158-62. 